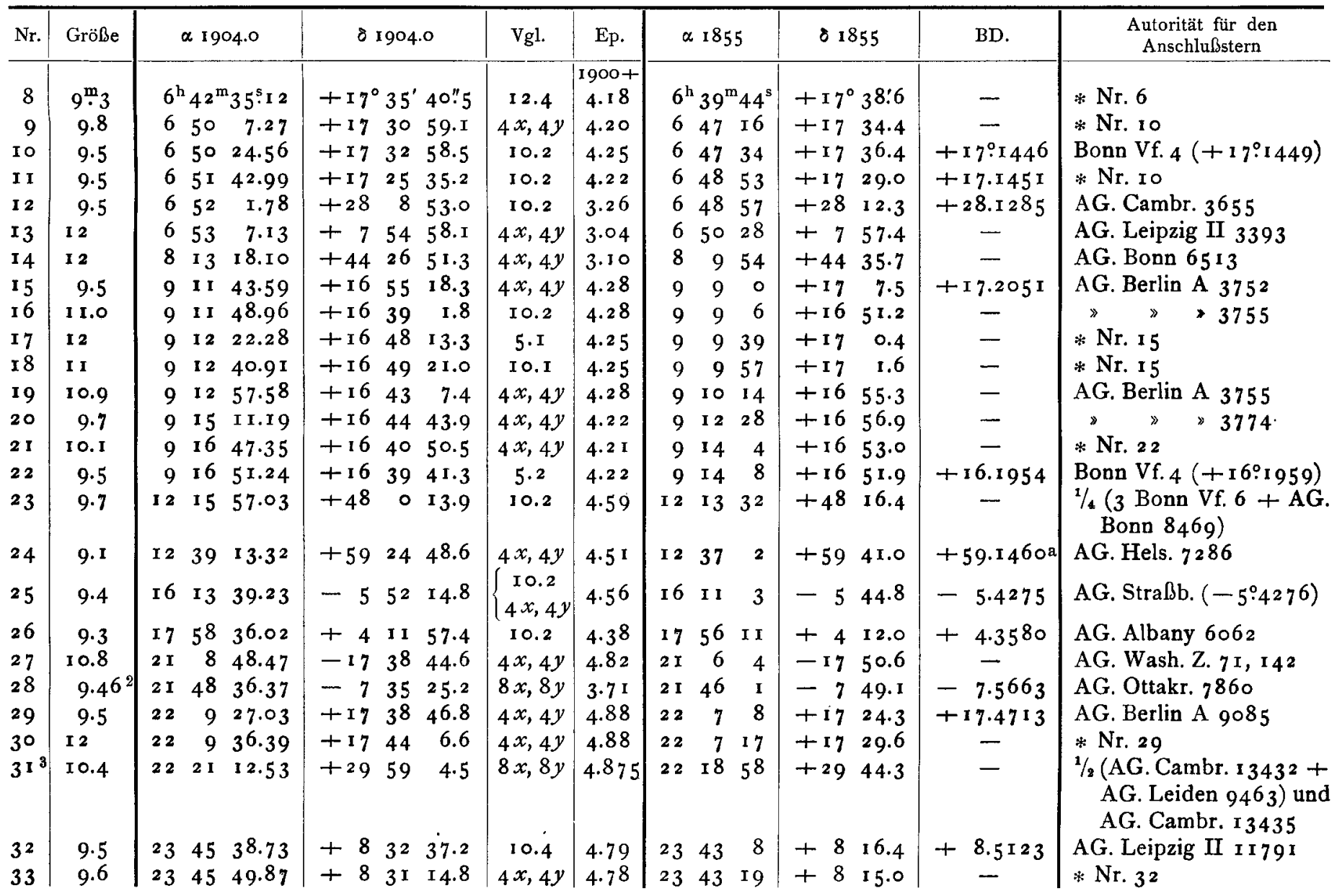

2 Photometrische Bestimmung am Keilphotometer; verbunden mit $-7^{\circ} \cdot 5669$ nach Ann. Harv. Coll. Obs. vol. $457^{\mathrm{m}} \cdot 44$.

${ }^{8}$ Var. RV Pegasi (A. Stanley Williams).

Straßburg i. E., I 904 Nov. 30 .

C. W. Wirtz.

\title{
Elemente und Ephemeride des Kometen 1904 e.
}

(Telegramm von Prof. Pickering d. d. Februar Io.)

The following elliptical elements were computed by Aitken from observations January 0, I7 and 27.

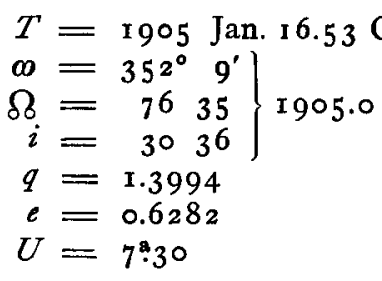

Ephemeris I $^{\text {h }}$ Gr.

\begin{tabular}{|c|c|c|c|}
\hline 1905 & RA. & PD. & I \\
\hline Febr. I I & $3^{8^{\circ}} 40^{\prime}$ & $67^{\circ} 30^{\prime}$ & 0.57 \\
\hline 15 & $4 \mathrm{I}$ & 6510 & \\
\hline I 9 & $434 \mathrm{I}$ & $62 \quad 57$ & \\
\hline 23 & 4621 & $60 \quad 52$ & 0.48 \\
\hline
\end{tabular}

Elemente des Kometen 1904 e.

Nachdem eine aus I 904 Dez. 3 I (Normalort aus 7 Be- übrig gelassen hatte, habe ich auf Anraten von Prof. H. Kreutz obachtungen), r905 Jan. 4 (Rom) und Jan. Io (Wien) ge- aus den beiden äußeren Örtern und der mir gütigst mitgerechnete Parabel im mittleren Ort den nicht wegzubringenden teilten Kopenhagener Beobachtung Fehler von $\mathrm{d} \lambda=-\mathrm{r} 6^{\prime \prime 2}, \mathrm{~d} \beta=+3.6$ im Sinne $\mathrm{B}-\mathrm{R}$

Jan. $268^{\mathrm{h}} 53^{\mathrm{m}} 22^{\mathrm{s}}$ Kopenhagen $\alpha$ app. $=\mathrm{I}^{\mathrm{h}} 59^{\mathrm{m}} 5^{\mathrm{s}} 27(9.408) \quad \delta$ app. $=+\mathrm{II}^{\circ} 5 \mathrm{I}^{\prime} 8$ ".० $^{(0.807)}$ Pechüle 